NBER WORKING PAPER SERIES

\title{
CONTROLLING THE COST OF MINIMUM BENEFIT GUARANTEES IN PUBLIC PENSION CONVERSIONS
}

\author{
Kent Smetters \\ Working Paper 8732 \\ http://www.nber.org/papers/w8732 \\ NATIONAL BUREAU OF ECONOMIC RESEARCH \\ 1050 Massachusetts Avenue \\ Cambridge, MA 02138 \\ January 2002
}

This paper was written while visiting the Department of Economics at Stanford University. Parts of this paper circulated under a different title in the past, and very helpful comments on previous drafts were received from John Campbell, Martin Feldstein, Bill Gale, Steven Ross, Elena Ranguelova, Jan Walliser, and seminar participants at the 1998 NBER Summer Institute, UC - Berkeley, Brookings Insitution, Michigan State, World Bank, Philadelphia Federal Reserve Bank, Congressional Budget Office, the 1999 AEA Association Meetings, and the January 15 - 16, 1999 NBER Conference Meetings held in Florida. Comments provided by anonymous referees helped improve the paper's exposition. The views expressed herein are those of the author and not necessarily those of the National Bureau of Economic Research.

(C) 2002 by Kent Smetters. All rights reserved. Short sections of text, not to exceed two paragraphs, may be quoted without explicit permission provided that full credit, including (C) notice, is given to the source. 
Controlling the Cost of Minimum Benefit Guarantees in Public Pension Conversions

Kent Smetters

NBER Working Paper No. 8732

January 2002

JEL No. G12, G13, G23

\begin{abstract}
Unfunded defined-benefit (DB) public pension plans throughout the world are being converted to funded defined-contribution (DC) plans that typically contain a minimum benefit guarantee (DC-MB). Risk management techniques must be used to control the cost of these guarantees. The most common technique is to "over-fund" the benefit: the contribution rate is set high enough so that the expected benefit is much larger than the guaranteed minimum benefit.

This paper shows that while over-funding is very effective in controlling guarantee costs in traditional DB plans, it is highly ineffective for DC-MB plans. This result holds even at very large contribution rates and when risky investments are restricted to a very diversified index like the S\&P500. Calculations show that the true risk-adjusted value of unfunded guarantees in a realistic DC-MB plan equals 40 to 90 percent (or more) of the value of the unfunded liability in the DB benefit being replaced, depending on design. This result is true even when the contribution rate in the DC-MB plan is chosen to produce an expected benefit five times larger than the DB benefit.

This paper considers two approaches to controlling guarantee costs. The first approach borrows from the recent catastrophic insurance literature. A "standardized" portfolio is guaranteed, requiring agents to accept "basis risk" if they chose a non-standard portfolio. However, for large conversions from DB to DC-MB plans, in which there is little or no DB benefit remaining, the government must still worry about any "implicit guarantee" extending beyond the standardized portfolio, thereby enticing agents to accept a lot of basis risk (a "Samaritan's Dilemma"). The second method, therefore, uses a more brute force approach: private portfolio returns in the good states of the world are taxed while returns in the bad states are subsidized. Both options are very effective at controlling guarantee costs, and they can be used separately or together. Calculations demonstrate that all of the unfunded liabilities associated with modern pay-as-you-go public pension programs can be eliminated under both approaches even at a modest contribution rate.
\end{abstract}

\author{
Kent Smetters \\ Deputy Assistant Secretary for Economic Policy \\ The United States Treasury \\ 1500 Pennsylvania Avenue, NW \\ Washington, DC 20220, \\ The Wharton School, University on Pennsylvania (on leave), \\ and NBER \\ Email: smetters@wharton.upenn.edu
}




\section{Introduction}

Pay-as-you-go public pension systems, like the US Social Security system, contain large unfunded liabilities. More funding, maybe as part of a privatization plan, could reduce burdens on future generations. But conversions of public pension systems to a system with individuallymanaged accounts often contain unfunded liabilities of their own. The main liability takes the form of a guarantee made by the government to each participant. Specifically, the government promises that each new private account will be large enough at the point of retirement to pay an annuitized benefit level above some minimum level. But assets, equal in value to the ex-ante cost of these guarantees are almost never set aside for this purpose. Instead, these guarantees are pay-as-you-go, or unfunded. Managing the cost of these guarantees, therefore, is critical to the success of any conversion. The most common technique currently being used to control these costs is to "overfund" the benefit: the contribution rate is set high enough so that the expected benefit is much larger than the guaranteed minimum benefit. But this paper shows that this technique is not very effective at controlling these costs. Two alternative methods are proposed, both of which are effective.

\section{Public Pension Conversions throughout the World}

Many countries have converted their public pension systems from pay-as-you-go DefinedBenefit (DB) plans to Defined-Contribution plans with Minimum Benefit guarantees (DC-MB). Chile's conversion began in 1981. The Chilean government guarantees that private accounts for new workers will produce a minimum pension payment equal to about 25 percent of average wages. The recently converted Mexican retirement system guarantees about 40 percent of average wages. Other countries with converted retirement systems include Argentina, Australia, Bolivia, Columbia, El Salvador, Hungary, Kazakhstan, Peru, Poland, Switzerland, and United Kingdom (CBO, 1998). ${ }^{1}$

\footnotetext{
${ }^{1}$ Some countries supplement only private accounts with small balances at the point of retirement, the focus on this paper. Other countries provide a pay-as-you-go benefit to everyone, which is generally more expensive.
} 
The United States has not yet begun the process of converting its public pension system to a system based in part on private accounts. But considerable debate is now taking place. Many of the plans being discussed include minimum benefit guarantees, including the plans by Feldstein and Samwick (1997, 2000). The original Feldstein-Samwick(1997) plan would convert the entire Social Security system to private accounts. Their newer "lite" version (2000) would introduce private accounts to augment a reduced, but still positive, level of Social Security benefit that can be afforded in the future at today's payroll tax rate. ${ }^{2}$ In both of their plans, pensioners receive a combined (public plus private) benefit at least equal in value to the present-law Social Security benefit level. ${ }^{3}$ Policymakers have also began devising their own plans with benefit guarantees. In the proposal by US Senator Phil Gramm (1998), for example, the government would guarantee that a worker receives an annuitized benefit equal to the amount that they would have received under Social Security plus twenty percent of the value of the investment they build up "over their working lives."

\section{The Cost of Guarantees}

Among academics, it is becoming more appreciated in recent years that benefit guarantees can be quite costly. The cost of pension guarantees have been analyzed in papers by Pesando (1982), Marcus (1985, 1987), Bodie and Merton (1993), and, most recently, Bodie (2001). ${ }^{4}$ Smetters (2001) focuses on recent privatization plans, including the Feldstein-Samwick (1997) plan and the Gramm (1998) plan. He shows that unfunded minimum benefit guarantees can be costly enough to undo

\footnotetext{
${ }^{2}$ Due to long-term insolvency problems facing Social Security, maintaining present-law benefit levels requires increasing the payroll tax rate from 12.3 percent of payroll to over 19 percent (Social Security Trustees, 2000). The Feldstein-Samwick "lite" plan would increase funding today in order to avoid a payroll tax increase in the future. Hence, Feldstein and Samwick are tackling the hardest baseline, rather than a baseline with smaller benefits.

${ }^{3}$ Investment risk is addressed in Feldstein, Ranguelova and Samwick (2001) and in other articles by them referenced therein. US Social Security benefits for a person with average lifetime earnings is a little more than 40 percent of average wages. Hence, the level of guarantee needed in the Feldstein-Samwick plan is similar to Mexico's.

${ }^{4}$ In a different context, a recent interesting paper by Stanton (2000) demonstrates how many 401(k) plans give participants a valuable option to time retirement or rollovers.
} 
most of the salutary long-run benefit typically associated with funded private accounts. The 1997 Feldstein-Samwick plan, for example, would eliminate existing unfunded liabilities in the long run without a minimum benefit guarantee, but reduce them by only 15 percent if the government guaranteed that agents received at least the present-law Social Security benefit level. The guarantee in the Gramm plan would likely increase unfunded liabilities. The current paper considers strategies to control these guarantee costs.

\section{The Standard Method of Controlling Guarantee Costs: Over-funding}

As explained in Bodie and Merton (1993), an effective method of managing the risk associated with fixed guaranteed benefits inside traditional DB plans is as follows: frequently mark fund assets and liabilities to market prices, adjust fund income (i.e., employer contributions) to match assets with liabilities, and over-fund the expected benefit. Over-funding means that the DB fund holds more assets than necessary to pay future benefits, if asset returns take their expected values. Over-funding creates a buffer against shocks between the dates in which fund assets and liabilities are marked to market. Over-funding, therefore, reduces the need to sharply adjust employer contributions in response to price shocks.

In DC plans containing minimum benefit guarantees (DC-MB), frequent marking to market, with subsequent changes in income flows to private accounts, is intractable. Frequent marking would require frequently adjusting a worker's contribution rate. Moreover, private accounts would have to be individually marked because, unlike a DB plan with a single portfolio, portfolio risk in a DC-MB plan depends on a worker's choice. No country with a DC-MB plan incurs these administrative costs. Chile, for example, has not changed its contribution rate after inception twenty years ago, much less implemented individual contribution rates. ${ }^{5}$

\footnotetext{
${ }^{5}$ Chile penalizes participating mutual funds that under-perform relative to the mean return. However, it is the risk in the mean return itself, associated with a broad portfolio, which is the focus of this paper.
} 
Instead, the primary risk management technique employed by DC-MB plans is over-funding. In particular, the mandatory payroll contribution rate in the DC-MB system is chosen so that the expected cross-sectional average benefit level is significantly larger than the guarantee minimum benefit level. For example, the mandatory contribution rate in Chile is 10 percent of payroll, which is generally believed to produce an average expected benefit level that is significantly larger than the minimum benefit level. The same approach has been taken in Argentina (11 percent of payroll), Mexico ( $81 / 2$ percent of payroll), and is the dominate strategy in most countries. ${ }^{6}$

The over-funding strategy has also been considered pension reform in the United States. As Bodie (1995) clearly demonstrates, the standard investor lore that stock holdings become low risk if held for a long time is misguided. Still, Feldstein, Ranguelova, and Samwick (2001) do present monte carlo evidence suggesting that their privatization plan fails, with only a modest to small probability, to produce a retirement benefit at least equal to what pensioners would have received under Social Security. The probability of shortfall becomes smaller as the contribution rate is increased. Hieger and Shipman (1997) present some limited monte carlo evidence to argue that a large enough payroll tax (taken as today's contribution level) would, if invested in stocks, fail to produce the current Social Security benefit with only a small probability. Senator's Gramm plan would require smaller contributions, equal to about $8 \frac{1}{2}$ percent of payroll which, by his staff's calculations, would still produce an expected benefit several times larger than Social Security. But these types of probability calculations do not capture the large utility value, as reflected in the equity premium, that the market places on protection against large shortfalls, even though uncommon.

\footnotetext{
${ }^{6} \mathrm{CBO}$ (1998) provides an overview of the literature analyzing the Chilean pension plans. Several of the DCMB plan in developing countries have domestic investment restrictions in order to encourage domestic capital market development. These restrictions, combined with undeveloped domestic capital markets, poses additional risks.
} 
Section III shows that the popular over-funding approach to controlling guarantee costs, while effective for DB plans, has very little effect in DC-MB plans. ${ }^{7}$ This surprising result holds even at large contribution rates, and even when risky investments are restricted to a very diversified stock index like the S\&P500. Calculations show that the ex-ante value of unfunded liabilities in realistic DC-MB plans equal about 40 to 90 percent (or more) of the unfunded liability of the guaranteed DB benefit being replaced, depending on design. This fact is true even when the contribution rate in the $\mathrm{DC}-\mathrm{MB}$ plan is chosen to produce an expected benefit five times larger than the DB benefit.

A large amount of the guarantee cost stems from moral hazard. As proven in Section III, agents will only hold risky stocks in their DC-MB account in order to maximize the value of the guarantee. Bonds are only held in their non-mandatory private saving accounts (with assumed identical tax status). Any risk management method to control the cost of guarantee risk must, in part, therefore, reverse this excessive risk taking.

\section{$\underline{\text { New Risk Management Techniques are Needed }}$}

New risk management techniques, therefore, are needed to control the cost of guarantees. Like Smetters (1998), Feldstein and Ranguelova (2000), for example, suggest that participants in DC-MB plans could sell part of their upside potential (taking the short side of a call option) as a means for paying for downside protection (taking the long side of a put option). Unlike Smetters (1998), however, Feldstein and Ranguelova suggest that these securities could be provided by the private market at a reasonable cost, whereas Smetters focused on government provision as an integral part of prefunding Social Security. The problem with relying on the private market is that

\footnotetext{
${ }^{7}$ Some preliminary analysis on this point was also presented in Smetters (2001), although the reasoning is flushed out in much more detail herein. Moreover, the model herein is more detailed and this paper considers remedies.
} 
these options require long maturity dates and the private market has already revealed it's unwillingness to provide them. In fact, the longest maturity period currently available for options is three years. Moreover, the market for these securities (indexed LEAPS) is very thin, probably since the securities are much costlier than the price suggested by the standard option pricing formula, like that used by Feldstein and Ranguelova. Achieving prices consistent with standard option pricing formula would, at a minimum, require smoothing risks between generations -- a task that requires the use of the government's taxing authority. Another problem is that rational agents won't hold protection against downside risk in their guaranteed accounts unless they're forced (see below). A good risk management technique would allow for portfolio choice due to preference heterogeneity.

\section{Overview of this Paper}

New strategies of risk management, therefore, are needed in the new era of DC-MB accounts. The remainder of this paper considers two methods of controlling the cost of a benefit guarantee. The first method, analyzed in Section IV, borrows an idea from the recent catastrophic insurance literature. The guarantee is placed over a "standardized" portfolio, requiring agents to accept any "basis risk" if they chose a non-standard portfolio. ${ }^{8}$ However, the usefulness of this method is probably limited to smaller DB to DC-MB conversions, like those being discussed in the United States, in which at least a modest DB benefit remains. The reason is that even though this technique, in theory, works well at reducing moral hazard, agents might, as a practical matter, anticipate an “implicit guarantee” and, therefore, assume a lot of basis risk - a so-called Samaritan's Dilemma. The second method, analyzed in Section V, therefore, involves a little more brute force while still allowing for a fair amount of portfolio selection. It taxes assets in DC-MB accounts in good states of the world and subsidies assets in bad states of the world. This approach is generally more flexible

\footnotetext{
${ }^{8}$ See Doherty and Smetters (2001) for the motivation of catastrophic risk contracts. The usefulness of indexed contracts in pension reform was triggered by two very helpful conversations with Andrew Samwick and Martin Feldstein.
} 
relative to a stock-bond portfolio mandate. Both methods effectively reduce guarantee costs, and they can be used separately or together. Calculations show that all of the unfunded liabilities associated with modern pay-as-you-go public pension programs can be eliminated under both approaches, even at a modest contribution rate. Section VI concludes.

\section{Intuition}

It is not immediately intuitive why over-funding retirement benefits only barely reduces the value of unfunded liabilities in defined contribution plans with minimum benefit guarantees (DC$\mathrm{MB})$. So this section presents a simple example to illustrate the key conceptual points before diving into the model presented in Section III. ${ }^{9}$ The example is then used to show why over-funding is effective in traditional DB plans. Finally, remedies for reducing liabilities in DC-MB plans are illustrated. This section was added in response to feedback I received by several readers desiring a firmer grasp of the intuition. It can be skipped without much loss in continuity.

\section{The Ineffectiveness of Over-Funding in Reducing Liabilities in DC-MB plans}

Suppose that a $\$ 1$ payroll contribution is invested in risky stocks for 30 years and that the following gross annual average internal real rates of return can occur with $14^{\text {th }}$ probability: $\{0 \%$, $103 \%, 110 \%, 120 \%\} .{ }^{10}$ Hence, in 30 years, the investment will be worth one of the following values with $14^{\text {th }}$ probability: $\left\{\$ 0^{30}, \$ 1.03^{30}, \$ 1.10^{30}, \$ 1.20^{30}\right\}=\{\$ 0.0, \$ 2.43, \$ 17.45, \$ 237.38\}$. Suppose that the government guarantees that the $\$ 1$ investment will be worth $\$ 5$ in 30 years. This guarantee, therefore, pays off if either the $0 \%$ state (producing $\$ 0.0$ ) or the $103 \%$ state (producing $\$ 2.43$ ) are realized. However, the lion's share of the guarantee value is associated with the really bad $0 \%$ state.

\footnotetext{
${ }^{9}$ I am grateful to Zvi Bodie, John Campbell, Martin Feldstein, and Steven Ross for their insights.

${ }^{10}$ A zero gross return is allowed as a possible discrete outcome in order to incorporate a limiting state of the continuous log-normal distribution. It is not necessary. The calculations presented later assume log-normal returns.
} 
The high value stems from the fact that (i) the number of dollars paid by the government is highest in that state $(\$ 5-\$ 0=\$ 5)$ and, (ii) the value of each dollar paid in that bad state carries lots of utility value in the presence of risk aversion. ${ }^{11}$

Suppose, to reduce the guarantee's value, the government requires that people double their payroll contribution to $\$ 2$. Now the possible asset value outcomes also double and become $\{\$ 0.0$, $\$ 4.86, \$ 34.90, \$ 474.76$. If the $103 \%$ state (producing $\$ 4.86$ ) is realized then the government only pays $\$ 0.14(\$ 5$ - \$4.86) under a $\$ 2$ contribution level instead of $\$ 2.57(\$ 5-\$ 2.43)$ under the $\$ 1$ level. Hence, increasing the contribution level from $\$ 1$ to $\$ 2$ reduces the government's liability by $\$ 2.43$ $(\$ 2.57-\$ 0.14)$ in this state. But notice that the higher contribution level did not reduce the value of the guarantee associated with the bad $0 \%$ state, where most of the guarantee value is derived.

Suppose that the government triples the contribution level to $\$ 3$. Now the possible asset value outcomes also triple and become $\{\$ 0.0, \$ 7.29, \$ 52.35, \$ 712.14\}$. This increase in the contribution rate reduces the cost of the $\$ 5$ minimum benefit guarantee even more. The government now owes nothing if the $103 \%$ state is realized. However, the government's liability is now reduced by only $\$ 0.14$ in this state relative to the $\$ 2$ contribution level. (In contrast, recall that the government saved $\$ 2.43$ in this state when the contribution rate was increased from $\$ 1$ to $\$ 2$.) Again, no money is saved on the costly $0 \%$ state.

Now suppose the government increases the contribution level to $\$ 4$. The 30 -year asset set is now $\{\$ 0.0, \$ 9.72, \$ 69.80, \$ 949.52\}$. Notice that this policy change has had no marginal impact on the value of the guarantee. The reason is that the $103 \%$ state was already above the guarantee

${ }^{11}$ Formally, suppose state $s$ in the state space $S$ occurs with probability $\pi(s)$ and let $p(s)$ be the price of an (Arrow) security that pays one unit of consumption in state $s$. An investor maximizes expected utility $\sum \pi(s) u(c(s))$ subject to the budget constraint $\sum p(s) \cdot c(s) \leq W$, where $W$ is his/her wealth today. Then $p(s)=\frac{1}{\lambda} \pi(s) u^{\prime}(c(s))$ where $\lambda$ is the marginal utility of wealth. Hence, bad states are characterized by a high marginal utility and high Arrow prices. 
level at a $\$ 3$ contribution. Moreover, again, the contribution level has no impact on the $0 \%$ state.

In sum, one should suspect that (i) over-funding is not very effective at controlling guarantee costs in DC-MB plans because over-funding has little impact on the really bad - and mostly costly - states of the world, and (ii) over-funding's marginal impact at reducing costs is even lower at higher levels of funding. The above example is trivial, but the same mechanics are at work in the model below. Indeed, the reader can replace the $0 \%$ state event, which was used to simplify the presentation, with a positive value like $10 \%$. Before summarizing the intuition for these results, I consider some examples of effective risk management.

\section{The Effectiveness of Over-Funding in Reducing Liabilities in Traditional DB Plans}

Let's continue with the example, except change the guarantee form. As before, the following gross annual real rates of return of return to stocks can occur with $14^{\text {th }}$ probability: $\{0 \%, 103 \%$, $110 \%, 120 \%$. Hence, as before, the final assets in 30 years will take one of the values in the following set with $1 / 4^{\text {th }}$ probability at the $\$ 1$ contribution level: $\{\$ 0.0, \$ 2.43, \$ 17.45, \$ 237.38\}$. But suppose instead of guaranteeing a minimum benefit equal to $\$ 5$, the government instead guarantees a fixed benefit equal to $\$ 5$, like in a traditional DB plan. In other words, if the value of assets in a new DC-MB account at retirement is below $\$ 5$, the government subsidizes that account to bring its value up to $\$ 5$. But if retirement assets exceed $\$ 5$ then the government taxes away all of the difference. Hence, the government faces a state-contingent liability in the following set, each with a ${ }^{1 / 4}$ th probability: $\{\$ 5-\$ 0, \$ 5-\$ 2.43, \$ 5-\$ 17.45, \$ 5-\$ 237.38\}=\{\$ 5, \$ 2.57,-\$ 12.45,-\$ 232.38\}$. Notice that the government's liability is negative in the $110 \%$ and $120 \%$ states, whereas its liability was zero in these states in the minimum benefit example above.

What is important is not the exact numbers but how they change with the contribution rate. Like before, doubling the contribution to $\$ 2$ changes the 30 -year asset set to $\{\$ 0.0, \$ 4.86, \$ 34.90$, 
$\$ 474.76\}$. The liability set under the fixed benefit guarantee now becomes $\{\$ 5-\$ 0, \$ 5-\$ 4.86, \$ 5$ -

$\$ 34.90, \$ 5-\$ 474.76\}=\{\$ 5, \$ 0.14,-\$ 29.9,-\$ 469.76\}$, whereas it was $\{\$ 5, \$ 0.14, \$ 0, \$ 0\}$ under the minimum guarantee. While doubling the contribution rate has little impact on the liability set associated with the minimum guarantee, the change is significant under the fixed guarantee. The reason is that the government now collects lots of revenue in the good states of the world (negative liabilities). As shown later, the ex-ante value of receipts collected in the good states can actually exceed the ex-ante value of the liabilities in the bad states. I.e., the government can more than overfund its way out of an costly fixed guarantee.

\section{Controlling Guarantee Costs in DC-MB Plans}

One way, therefore, to reduce guarantee costs in DC-MB plans is to partly mimic a DB plan by taxing retirement assets in DC-MB accounts in good states of the world, i.e., if assets exceed a threshold value at retirement. A tax in good states of the world helps compensate ex-ante the subsidy given in bad states. The extreme form of this approach is a traditional funded DB benefit plan which, in effect, taxes 100 percent of any benefit in excess of the guaranteed minimum benefit, while fully subsidizing the downside. This type of state-contingent taxation is considered below.

But another approach, also considered herein, would be for the government to only guarantee a "standardized" portfolio of assets, as in many modern catastrophic risk contracts. Agents would be required to accept any "basis risk" to the degree that they chose a non-standard portfolio. For example, suppose that a $\$ 1$ contribution today has an equal chance of being worth either $\$ 10$ or $\$ 20$ in 30 years if $\$ 0.50$ is invested in a broad stock index and $\$ 0.50$ is invested in bonds. We will call this 50-50 stock-bond split the "standardized" portfolio. The government guarantees that this standardized portfolio will produce a benefit equal to $\$ 15$. So the government faces a liability equal to $\$ 5$ if the bad $(\$ 10)$ state is realized. Suppose that an investor, however, chooses to invest the entire $\$ 1$ in stocks, which yields retirement assets $\$ 0$ in the bad state or $\$ 40$ in the good state with 
equal probability. If the bad state is realized, the government only pays out the amount that it would have owed in the bad state had the investor chosen the standardized 50-50 stock-bond split, or \$5. The investor bears the other $\$ 10$ of the $\$ 15$ minimum benefit as basis risk, which is the cost of deviating from the standardized portfolio.

To illustrate how guaranteeing a standardized portfolio could effectively control costs, let's return to our previous example. As before, the gross annual real rates of return of return to stocks can take one the following values with $1 / 4^{\text {th }}$ probability: $\{0 \%, 103 \%, 110 \%, 120 \%\}$. Suppose that the standardized portfolio is composed of a 50-50 split between stocks and bonds, and suppose that the gross annual return to risk-less bonds is $100 \%$ (i.e., zero net return). Then the gross annual real rates of return of return in the standardized portfolio can take one the following values with $1 / 4^{\text {th }}$ probability: $\{50 \%, 101.5 \%, 105 \%, 110 \%\}$. Notice that standardization, therefore, lifts resources in the bad state of the world by reducing resources in the good states. Moreover, standardization eliminates the absorbing state.

However, while in theory guaranteeing a standardized portfolio works well at reducing moral hazard, agents might, as a practical matter, anticipate an "implicit guarantee" and, therefore, assume a lot of basis risk - a so-called Samaritan's Dilemma. For the smaller type of conversion being discussed in the United States, in which at least a modest DB benefit remains, the standardization approach probably avoids this problem. But the risk of a Samaritan's Dilemma is problematic for large reforms that leave little DB benefit in place. In this case, state contingent taxes are needed.

\section{$\underline{\text { Summary }}$}

The intuition why the common over-funding approach is less effective in reducing liabilities relative to the two alternative approaches analyzed herein can be summarized as follows. The overfunding strategy proportionally increases retirement resources in every non-absorbing state of the world (and has no effect in the absorbing state where all assets are lost). In contrast, the alternative 
methods - state-contingent taxation and standardization - shift resources from the good states of the world to the bad states (and, in the process, also eliminate absorbing states). In effect, the payoff in each bad state is being partly financed by reducing the payoffs in the good states. As a result, for the same contribution rate, unfunded liabilities are lower under these two remedies relative to the traditional over-funding approach which does not perform this shift. Equivalently, state-contingent taxation and standardization can achieve the same reduction in unfunded liabilities as the overfunding approach, but at a smaller payroll contribution rate.

\section{The Change in Unfunded Liabilities in DB to DC-MB Conversions}

This section shows that conversion from an unfunded DB system with a fixed benefit to a funded DC system with a minimum benefit guarantee (DC-MB) fails to significantly reduce unfunded liabilities, thereby failing to achieve a major objective of pension reform. This result holds even at very high contribution rates in the DC-MB system, which are meant to over-fund the expected benefit. Remedies are considered later.

The generation- $t$ agent lives for two periods and her expected lifetime utility equals,

$$
E_{t}\left\{\sum_{j=1}^{2} \lambda^{j} U\left(c_{j, t+j-1}\right)\right\}
$$

where $c_{j, t}$ is the consumption at age $j$ in year $t$ and $\lambda$ is the discount factor.

The generation- $t$ agent earns wage income $w_{t}$ revealed at the start of year $t$, consumes $c_{1, t}$ at age 1 and saves the difference, $s_{t}$. A share of savings, $\alpha_{t}$, is invested into risk-free bonds that pay $r_{t+1}$ in year $t+1$. The other $\left(1-\alpha_{t}\right)$ share is invested into equities paying a risky return $e_{t+1}$ in year $t+1$. The individual faces a Social Security payroll tax equal to $\tau^{S}$, the proceeds of which are invested into a pay-as-you-go Social Security asset that pays an internal rate of return $g_{t+1} \equiv\left(w_{t+1} / w_{t}\right)-1$. Before pension reform takes place, the individual's budget constraints are: 


$$
\begin{gathered}
S_{t}=\left(1-\tau^{S}\right) w_{t}-c_{1, t} \\
c_{2, t+1}=s_{t} \cdot\left[\left(1+r_{t+1}\right) \alpha_{t}+\left(1+e_{t+1}\right)\left(1-\alpha_{t}\right)\right]+\tau^{S} w_{t}\left(1+g_{t+1}\right)
\end{gathered}
$$

The agent chooses the level of saving, $s$, and the portfolio share, $\alpha$, to maximize equation (1) subject to the constraints (2) and (3). The first-order conditions are:

$$
\begin{aligned}
& U^{\prime}\left(c_{1, t}\right)=\lambda\left(1+r_{t+1}\right) E_{t}\left[U^{\prime}\left(c_{2, t+1}\right)\right] \\
& U^{\prime}\left(c_{1, t}\right)=\lambda \cdot E_{t}\left[\left(1+e_{t+1}\right) \cdot U^{\prime}\left(c_{2, t+1}\right)\right]
\end{aligned}
$$

The stock price process is described by an Itô-type stochastic differential equation and, without loss in generality, has a stationary expected yield $\bar{e} \equiv E_{t}\left(e_{t+1}\right) .{ }^{12}$ While $r=\bar{e}$ for linear utility, the inequality $\bar{e}>r_{t+1}$ holds with risk averse preferences (i.e., $U^{\prime}>0, U^{\prime \prime}<0$ ).

\section{A Stylized Conversion Proposal}

Conversion to private accounts begins with generation 1 , the current workers. Generation- 0 agents, the current elderly, continue to receive benefits under the current pay-as-you-go (unfunded) Social Security system. These benefits are paid by generation 1 who receives nothing from Social Security. Hence, generation 1 bears the entire transition cost required of greater funding. Generation-1 agent faces a new mandatory payroll tax, $\tau^{M}$, on top of their existing Social Security payroll tax. The mandatory contribution is invested into a private account to replace the lost Social Security benefit. Generation 2, and all subsequent generations, no longer face the Social Security tax rate but instead contribute only $\tau^{M} \cdot w_{t}$ to their new mandatory private account. Let $\beta_{t}$ denote the fraction of the new mandatory private account which is invest in the risk-less asset, and let $1-\beta_{t}$ represent the fraction invested in equities.

The government guarantees that the new mandatory private account for each generation $t(t$

\footnotetext{
${ }^{12}$ Arbitrage pricing will be used below to value marginal changes, allowing us to derive closed-form solutions. This approach also allows market prices to speak for risk aversion instead of forcing us to defend particular forms of preferences and technology.
} 
$\geq 1$ ) will replace at least some fraction, $\chi$, of the benefit that generation $t$ would have received under Social Security, i.e., $\chi \cdot \tau^{S} w_{t}\left(1+g_{t+1}\right)$. A value of $\chi=1$ means that the new account yields a benefit at least equal to the benefit that an agent would have receive under Social Security. This guarantee is paid using a state-contingent tax on the wage income of generation $t+1$ :

$$
\tau_{t+1}^{c}=\frac{\max \left\{0, \chi \cdot \tau_{t}^{S} w_{t} \cdot\left(1+g_{t+1}\right)-\tau^{M} w_{t} \cdot\left[\left(1+r_{t+1}\right) \cdot \beta_{t}+\left(1+e_{t+1}\right) \cdot\left(1-\beta_{t}\right)\right]\right\}}{w_{t+1}}
$$

The new budget constraints for generation $t \geq 2$, after pension reform, are now

$$
\begin{gathered}
s_{t}=\left(1-\tau^{M}\right) w_{t}-c_{1, t} \\
c_{2, t+1}=s_{t} \cdot\left[\left(1+r_{t+1}\right) \alpha_{t}+\left(1+e_{t+1}\right)\left(1-\alpha_{t}\right)\right]+ \\
\tau^{M} w_{t} \cdot\left[\left(1+r_{t+1}\right) \beta_{t}+\left(1+e_{t+1}\right)\left(1-\beta_{t}\right)\right]+\tau_{t+1}^{c} w_{t+1}
\end{gathered}
$$

Now generation $t$ chooses $S_{t}, \alpha_{t}$, and $\beta_{t}$ to maximize equation (1) subject to constraints (2') and (3'). Denote the optimal values of these variables with asterisks $\left(^{*}\right)$.

Proposition 1. $\beta_{t}^{*}=0$. I.e., all assets in the new mandatory account are invested in equities.

Proof. Let $M_{t} \equiv \lambda u^{\prime}\left(c_{2, t+1}\right) / u^{\prime}\left(c_{1, t}\right)$. Suppose $\beta_{t}^{*}>0$. Then $\alpha_{t}^{*}$ could be increased by
$\beta_{t}^{*} \tau^{M} w_{t} / s_{t}^{*}$ and $\beta_{t}$ could be decreased to zero. The sum of the first two terms on the right-hand side of equation ( $\left.3^{\prime}\right)$ does not change, but the value of the contingent tax payment received from generation $t+1, E_{t}\left[M_{t} \cdot \tau_{t+1}^{c} w_{t+1}\right]$, increases. So $\beta_{t}^{*}>0$ could not have been optimal. Q.E.D.

In words, a rational agent would be throwing away some guarantee value by holding bonds in their new mandatory portfolio; they should instead hold all their bonds in their non-mandatory portfolio (assuming equal tax status). The proof formally assumes that $\alpha$ is not bound between zero and unity, i.e., there are no short-sale constraints in the non-mandatory private portfolio. But that assumption is innocuous. If agents wanted to hold a negative amount of stocks in their non- 
mandatory private portfolio, the capital market would allow them to do so since those short positions

could be fully collateralized by the long positions in the mandatory guaranteed portfolio. ${ }^{13}$ The market would not forego such an obvious no-risk (arbitrage) possibility. Indeed, despite the private market's general unwillingness to write non-collateralized long-term contracts, this type of contract is fully collateralized and, therefore, guaranteed to exist under no-arbitrage conditions. ${ }^{14}$ To prevent this type of market from occurring, the government would have to explicitly outlaw these types of contracts. However, that situation is unlikely to happen for two reasons. First, it would be a regressive policy that would allow wealthier individuals, who are unlikely to run up against shortsale constraints, to exploit the guarantee more than the poor. Second, it would be extremely costly to enforce since it would be easily for financial institutions to verify portfolio holdings of agents.

With $\beta_{t}^{*}=0$, the new mandatory contribution rate, $\tau^{M}$, that is needed to produce an expected benefit equal to $\Psi$ times the Social Security benefit expected under the previous system is

$$
\tau^{M} \equiv \frac{\psi \cdot \tau^{s}(1+\bar{g})}{(1+\bar{e})}
$$

where $\bar{g}$ is the stationary expected wage growth rate. Moreover, the state-contingent tax equals,

$$
\tilde{\tau}_{t+1}^{c}=\frac{\max \left\{0, \chi \cdot \tau_{t}^{S} w_{t} \cdot\left(1+g_{t+1}\right)-\tau^{M} w_{t} \cdot\left(1+e_{t+1}\right)\right\}}{w_{t+1}}
$$

\footnotetext{
${ }^{13}$ For example, consider a person who must contribute $\$ 11$ into his mandatory account and who saves an additional $\$ 9$, for a total of $\$ 20$. Suppose that with the guarantee over the mandatory account in place, this person would like to save $\$ 10$ in stocks and \$10 in bonds. This person could hold \$11 in stocks in his mandatory account while holding -\$1 in stocks (a short position) and \$10 in bonds in his non-mandatory account.

14 The financial market has demonstrated enormous creativity in writing contracts to game social insurance. The Wall Street Journal (June 6, 2001) reports that insurance companies now offer annuities that convert assets into income that allow even affluent people to qualify for Medicaid. (I am grateful to Mark Warshawsky for bringing this to my attention.) But, unlike the situation analyzed in the text, these securities exist even though they don't provide a pure arbitrage opportunity. Moreover, a government crackdown on these annuities make sense on progressivity grounds.
} 
The post-conversion percentage change in the unfunded liabilities in stochastic steady state is given by the ratio of the value of unfunded guarantee to the former unfunded benefit. For $\beta^{*}=0$,

$$
\begin{aligned}
\% \Delta_{M} & =\left\{1-\frac{E_{t}\left(M_{t} \cdot \tilde{\tau}_{t+1}^{c} w_{t+1}\right)}{E_{t}\left(M_{t} \cdot \tau_{t}^{s} w_{t+1}\right)}\right\} \cdot 100 \% \\
& =\left\{1-\frac{1+r}{1+\bar{e}} \cdot \psi \cdot E_{t}\left(M_{t} \cdot \max \left[0,\left(\frac{\chi(1+\bar{e})}{\psi}-1\right)-e_{t+1}\right]\right)\right\} \cdot 100 \% \\
& \equiv\left(1-\frac{1+r}{1+\bar{e}} \cdot \psi \cdot \hat{\Omega}\right) \cdot 100 \%
\end{aligned}
$$

where, as before, $M_{t} \equiv \lambda u^{\prime}\left(c_{2, t+1}\right) / u^{\prime}\left(c_{1, t}\right)$. The term $\frac{1+r}{1+\bar{e}}$ in (8) reflects the price of risk which negates any attempt to arbitrage between risk-free bonds and equities. The variable $\hat{\Omega}$ is the price of a one-period put option on a dollars worth of equities with a strike price of $\$ 1\left[\frac{\chi}{\psi}(1+\bar{e})\right]$ the next period. This strike price is intuitive. A larger expected benefit level $(\psi)$ requires a higher contribution rate $\tau^{M}$ by equation (7) and lowers the strike price. The reason is that more dollars are being contributed to private accounts and so each dollar does not have to perform as well in order to meet the minimum benefit. Similarly, a higher guaranteed minimum benefit level $(\chi)$ raises the strike price since each dollar must perform better in order to satisfy the guarantee.

The parameters in equation (8) are directly observable, or can be computed using observable prices. The value of the put option can be priced exactly, without any additional assumptions about the preferences beyond nonsatiation, using the Black-Scholes (1973) option pricing theorem. ${ }^{15}$ Price moments are assumed to fully incorporate all relevant information about preferences.

\footnotetext{
${ }^{15}$ My calculations are conservative. As noted in Section I, the standard option pricing formula tends to underestimate the value of a guarantee unless the shock is assumed to be shared across generations.
} 


\section{$\underline{\text { Computations }}$}

Table 2 reports values corresponding to equation (8) for various parameter choices shown in Table 1. Following the 2000 Social Security Trustees Report, the annual average the risk-free rate, $r$, is set equal to 3.0 percent and the economy's expected growth rate, $g$, is set at 1.0 percent per year. Privatization is compared against a solvent Social Security system current-law benefits. Solvency requires eventually increasing the Social Security payroll tax rate to about 19.25 percent. Following Feldstein and Samwick, the average annual social return to equities (including corporate tax payments), $\bar{e}$, equals 9 percent. The standard deviation of the first differences of logged real returns on the S\&P500 since 1928 equals 0.20 and 0.164 since 1949 . I conservatively chose 0.16 . Each period represents 30 years and all annual rates are converted to 30 -year equivalents. ${ }^{16}$

Whereas privatization with no guarantee $(\chi=0)$ would reduce unfunded liabilities by 100 percent, the presence of a realistic guarantee leads to much smaller reductions. See Table 2.

Consider the case $\{\psi=1.0, \chi=1.0, \beta=0.0\}$. In words, $\psi=1.0$ implies that the payroll tax rate is chosen so that the expected retirement benefit provided by the DC-MB account exactly equals the expected Social Security benefit. The equality $\chi=1.0$ implies that the government also guarantees that the DC-MB retirement benefit at least equals the expected Social Security benefit. The equality $\beta=0.0$ reflects the fact that rational agents invest all of their DC-MB assets is stocks (Proposition 1). The variable exp shown in Table 2 equals $\beta \cdot r+(1-\beta) \bar{e}$, the portfolio's annualized expected net real rate of return, which equals 9 percent for these parameter choices. This particular case was considered by Feldstein and Samwick (1997) using a detailed simulation model that did not include the market cost of risk. As shown in Table 2, the model herein closely replicates

\footnotetext{
${ }^{16}$ The choice of 30 years follows the two-period illustrative calculations presented in Feldstein and Samwick. Since there have been only two unique 30-year periods since 1928, price moments for the option pricing formula were calculated at an annual frequency and the time-to-maturity was taken as 30 years. This approach does not incorporate any slight mean reversion that might exist over a few years but it is still more conservative than using the standard deviation for 30-year non-overlapping periods. The use of 0.16 implicitly allows for some mean reversion.
} 
their two percent contribution level that they showed could be used to fully replace Social Security in the long run. While unfunded liabilities are eliminated without a guarantee in place, unfunded liabilities are reduced by only 18 percent with the guarantee. ${ }^{17}$ Intuitively, a payroll tax of only two percent places a large demand on the equity premium which is not exploitable herein. Guaranteeing that this equity premium will, in fact, materialize constitutes a large unfunded liability. Notice that in the case $\{\psi=2.0, \chi=1.5, \beta=0.0\}$, unfunded liabilities actually increase by 15 percent.

The Ineffectiveness of Over-funding at Reducing Unfunded Liabilities

Now suppose the government increases the contribution rate in order to reduce guarantee costs. Consider doubling the contribution level: $\{\psi=2.0, \chi=1.0, \beta=0.0\}$. Table 2 shows that privatization now reduces unfunded liabilities by 33 percent, up from 18 percent. Tripling the contribution level, $\{\psi=3.0, \chi=1.0, \beta=0.0\}$, leads to a 46 percent reduction. Increasing the contribution level by five times, $\{\psi=5.0, \chi=1.0, \beta=0.0\}$, leads to a 63 reduction, although expected benefits are now five times larger than the Social Security benefit that is being guaranteed. In fact, increasing the contribution level by ten times (not shown) leads to only a 83 percent reduction in unfunded liabilities despite a payroll tax rate of 20 percent. Two patterns, therefore, emerge, confirming the intuition given in Section II: (i) over-funding is not very effective at controlling guarantee costs in DC-MB plans and (ii) the marginal effectiveness of over-funding is even lower at higher levels of funding.

Table 2 also gives more specific detailed information to further help explain the ineffectiveness of over-funding. Notice that the value of the put option, $\hat{\Omega}$, in the two-percent accounts case, $\{\psi=1.0, \chi=1.0, \beta=0.0\}$, equals $\$ 4.50$. The implicit strike price in this case equals $\$ 1\left[\frac{\chi}{\psi}(1+\bar{e})\right]=\$ 1(1+\bar{e})=\$ 1 \cdot(1.09)^{30}=\$ 13.27$. In words, it costs $\$ 4.50$ to guarantee that

\footnotetext{
${ }^{17}$ These calculations are conservative, as they consider only marginal policy changes. Risk aversion implies that the marginal cost of the guarantee to taxpayers bearing the risk increases with the absolute size.
} 
a dollar invested today in stocks would be worth at least $\$ 13.27$ in 30 years from now. With a contribution level five times larger, $\{\psi=5.0, \chi=1.0, \beta=0.0\}$, the value of put option is $\$ 0.40$ and the implicit strike price is $\$ \frac{1}{5} \cdot(1.09)^{30}=\$ 2.65$. In words, it costs $\$ 0.40$ to guarantee that a dollar invested today in stocks would be worth at least $\$ 2.65$ in 30 years. Notice, therefore, that the guarantee cost per dollar invested in stocks has decreased by ten times, from $\$ 4.50$ to $\$ 0.40$. However, to get that reduction, five times more dollars must be invested and guaranteed. The net impact, therefore, is not large. The value of the guarantee per dollar invested would have to decrease by considerably more than ten times in order to significantly reduce net costs. The reason it does not, however, reflects the market value of insurance against very low equity returns, even if they are uncommon. Sections IV and V below examine two techniques that increase returns in the bad states of the world by reducing returns in the good states.

\section{$\underline{\text { Sensitivity Analysis }}$}

Tables $3 \mathrm{~A}$ and $3 \mathrm{~B}$ provide some sensitivity analysis to the results provided for the benchmark case. Table $3 \mathrm{~A}$ decreases $\bar{e}$ from 9 percent per year to 6 percent per year; a recent study commissioned by the Social Security Advisory Board (2001) motivates this assumed lower rate of return. Table 3B maintains the value of $\bar{e}$ at 6 percent and increases $\sigma$ to 0.20 .

Table 3A shows that the effect of assuming a lower value $\bar{e}$ is to reduce the unfunded liabilities associated with a parameter combination $\{\psi, \chi, \beta\}$ whenever $\beta<1$. The reason for the reduction is that a lower $\bar{e}$ requires a higher mandatory contribution rate $\tau^{M}$ and so less emphasis is being placed on the equity premium. Notice, for example, that $\tau^{M}$ increases from 2.0 percent of payroll in the case $\{\Psi=1.0, \chi=1.0, \beta=0.0 ; \bar{e}=0.09\}$ to 4.5 percent of payroll when in the case $\{\Psi=1.0, \chi=1.0, \beta=0.0 ; \bar{e}=0.06\}$. Whereas unfunded liabilities where reduced by 18 percent in the former case they are now reduced by 38 percent. At higher initial contribution levels, the 
impact is even small. Whereas unfunded liabilities decreased by 63 percent in the case $\{\psi=5.0$, $\chi=1.0, \beta=0.0 ; \bar{e}=0.09\}$, they decrease by 86 percent in the case $\{\psi=5.0, \chi=1.0, \beta=0.0 ; \bar{e}$ $=0.06\}$, despite the payroll tax increasing from 10 percent to 23 percent.

Table 3B shows that the effect of assuming a larger value of $\sigma$ is to increase the value of the minimum benefit guarantee. The value of $\sigma$ has no impact on the mandatory tax rate $\tau^{M}$ since the tax rate is based on expected returns, not risk. For $\{\psi=1.0, \chi=1.0, \beta=0.0 ; \bar{e}=0.06 ; \sigma=0.20\}$ shown in Table 3B, unfunded liabilities are reduced by 34 percent, compared with 38 percent shown in Table 3A when $\sigma=0.16$. For $\{\psi=5.0, \chi=1.0, \beta=0.0 ; \bar{e}=0.06 ; \sigma=0.20\}$, unfunded liabilities are reduced by 78 percent instead of 86 percent when $\sigma=0.16$. The value of $\sigma$ is slightly more important (in terms of percentage change in unfunded liabilities) at higher values of $\psi$ because a shift in the risk distribution becomes slightly more important at lower strike prices. However, since most of the value of the guarantee stems from protecting very low returns, the importance of $\sigma$ (in terms of percentage change in unfunded liabilities) is fairly uniform in $\psi$.

\section{Minimum Benefit Guarantee with a Standardized Portfolio}

Now suppose the government only insurers a "standardized" portfolio consisting of some bonds $(\beta>0)$. (Taxing benefits in good states of the world is added later.) Investors bear any "basis risk" if they choose a portfolio different from the standardized portfolio. With $\beta>0$, the new mandatory contribution rate, $\tau^{M}$, needed to produce an expected benefit $\psi$ times the expected Social Security benefit in the standardized portfolio is

$$
\tau^{M} \equiv \frac{\psi \cdot \tau^{s}(1+\bar{g})}{[(1+r) \cdot \beta+(1+\bar{e}) \cdot(1-\beta)]} .
$$

The state-contingent tax is still given by equation (6). The change in unfunded liabilities for the standardized portfolio now equals, 
$\% \Delta_{M}=\left\{1-\frac{E_{t}\left(M_{t} \cdot \tau_{t+1}^{c} w_{t+1}\right)}{E_{t}\left(M_{t} \cdot \tau_{t}^{s} w_{t+1}\right)}\right\} \cdot 100 \%$

$$
\begin{aligned}
& =\left\{1-\frac{(1+r) \cdot \psi \cdot(1-\beta)}{[(1+r) \cdot \beta+(1+\bar{e}) \cdot(1-\beta)]} \cdot E_{t}\left(M_{t} \cdot \max \left[0,\left(\frac{\chi[(1+r) \cdot \beta+(1+\bar{e}) \cdot(1-\beta)]-(1+r) \beta \psi}{\psi \cdot(1-\beta)}-1\right)-e_{t+1}\right]\right)\right\} \cdot 100 \% \\
& \equiv\left(1-\frac{(1+r) \cdot \psi \cdot(1-\beta)}{[(1+r) \cdot \beta+(1+\bar{e}) \cdot(1-\beta)]} \cdot \hat{\Omega}\right) \cdot 100 \%
\end{aligned}
$$

where $\hat{\hat{\Omega}}$ is the price of a one-period put option on a dollars worth of investment with a strike price

$$
\left(\frac{\chi[(1+r) \cdot \beta+(1+\bar{e}) \cdot(1-\beta)]-(1+r) \beta \psi}{\psi(1-\beta)}\right)=\left(\frac{(\chi-\psi)(1+r) \beta}{\psi(1-\beta)}+\frac{\chi}{\psi}(1+\bar{e})\right)
$$

Notice that, when $\beta=0$, the reduction in liability, $\left(8^{\prime}\right)$, and strike price, $(9)$, are the same as before.

Interior Case: $0<\beta<1$

It is easy to see that the value of the guarantee is reduced as the share of bonds, $\beta$, in the standardized portfolio is increased. A larger $\beta$ generates a larger mandatory contribution level, with all of the extra contribution invested into the risk-free asset. In fact, it is possible that the strike price, equation (9), could go negative, if enough bonds are held $(\beta \gg 0)$ and if the expected benefit is set much larger than the guaranteed benefit $(\psi \gg \chi)$. In this case, the portion of payroll contributions making its way into bonds is large enough that even a zero gross return to stocks, $(1+e)$ $=0$, satisfies the guarantee. Hence, the guarantee would have no value.

\section{Limit Case: $\beta \rightarrow 1$}

The guarantee has no value in the boundary case, $\beta=1$, with $\psi=\chi$. The standardized portfolio holds only risk-free bonds $(\beta=1)$ and the (deterministic) retirement benefit exactly equals the minimum benefit $(\psi=\chi)$. The strike price shown in equation (9) approaches zero, and so the 
option has no value.

When $\chi \neq \psi$, things get more complicated. The strike price diverges to positive [negative] infinity when $\chi>\psi[\chi<\psi]$ as $\beta \rightarrow 1$. Intuitively, the option for sure will pay off [not pay off] when $\chi>\psi[\chi<\psi]$. When $\chi>\psi$, the minimum benefit exceeds the final retirement benefit which is also deterministic since $\beta=1$; so the option must pay off. When $\chi<\psi$, the minimum benefit is less than the final retirement benefit which again is deterministic $(\beta=1)$; the option never pays off.

Hence, the option, as configured above, obviously has infinite value $(\chi>\psi)$ or no value $(\chi$ $<\psi)$. But the infinite value case need not worry us. Notice from equation ( $\left.8^{\prime}\right)$ that the value of the guarantee itself is composed of the put option pre-multiplied by an expression that converges to zero as $\beta \rightarrow 1$. Hence, we have the " $0 \cdot \infty$ " indeterminate form when $\chi>\psi$. We can algebraically manipulate out of the predicament (i.e., bifurcation is unnecessary). When $\beta=1$, the statecontingent tax rate becomes,

$$
\tilde{\tau}_{t+1}^{c}=\tau_{t}^{S} \cdot\left(1+g_{t+1}\right) \cdot \max \{0, \chi-\psi\} \quad(\text { for } \beta=1)
$$

and the change in unfunded liabilities becomes,

$$
\begin{aligned}
\% \Delta_{M} & =\left\{1-\frac{E_{t}\left(M_{t} \cdot \tau_{t+1}^{c} w_{t+1}\right)}{E_{t}\left(M_{t} \cdot \tau_{t}^{s} w_{t+1}\right)}\right\} \cdot 100 \% \\
& =\{1-\max [0, \chi-\psi]\} \cdot 100 \%
\end{aligned}
$$

In words, unfunded liabilities are reduced by less than 100 percent if the minimum benefit guarantee exceeds deterministic retirement assets $(\chi>\psi)$. But unfunded liabilities are fully eliminated if the minimum benefit guarantee is less than deterministic retirement assets $(\chi<\psi)$.

\section{$\underline{\text { Calculations }}$}

Table 2 shows that insuring only a standardized portfolio mixed with bonds is fairly effective at reducing unfunded liabilities. Consider, for example, the case $\{\psi=3.0, \chi=1.0, \beta=0.50\}$ in 
which half of the assets in the standardized portfolio are held in bonds. These parameter choices result in a 10 percent mandatory contribution rate. That tax rate is roughly same value as in the case considered in the last section, $\{\psi=5.0, \chi=1.0, \beta=0.0\}$, that used the over-saving strategy with no standardization of the guaranteed portfolio (and so agents rationally only held stocks in their MBDC accounts). Unfunded liabilities are reduced by 79 percent with the standardized portfolio, $\{\Psi$ $=3.0, \chi=1.0, \beta=0.50\}$, but by only 63 percent, using the over-funding strategy, $\{\Psi=5.0, \chi=1.0$, $\beta=0.0\}$. In other words, the moral hazard cost associated with failing to insure only a standardized portfolio is equal to 15 percent of the current unfunded liability. In dollar terms, for a unfunded liability of about $\$ 10$ trillion as in the US, the cost of moral hazard alone would be $\$ 1.5$ trillion.

As motivated in Section II, the greater effectiveness of the standardized portfolio approach in reducing unfunded liabilities stems from the fact that standardization shifts a portion of the payoff in the good states of the world to the bad states. In contrast, the over-funding approach proportionally increases the payoffs in each non-absorbing state of the world. So the over-funding approach does not subsidize returns in bad states with returns from the good states. The standardization approach, therefore, can produce a relatively larger payoff in bad states of the world at the same contribution rate.

Table 2 shows several cases in which standardization can be used to fully eliminate the exante value of unfunded liabilities in the DC-MB system. For example, in the case $\{\psi=1.0, \chi=1.0$, $\beta=1.0\}$, the contribution rate is a little below 11 percent and the standardized portfolio consists of only bonds. Unfunded liabilities are reduced by 100 percent. The same is true in the case, $\{\Psi=5.0$, $\chi=0.75, \beta=0.50\}$, where the standardized portfolio consists of a 50-50 split between stocks and bonds, but only three-quarters of the existing Social Security benefit level is guaranteed. The corresponding payroll tax rate equals $16^{1 / 2}$ percent, which is below the $19 \frac{1}{4}$ percent payroll tax rate eventually required under Social Security. The expected benefit in the new DC-MB plan with this 
configuration, however, is five times larger than the Social Security benefit. Unfunded liabilities are eliminated under these parameter settings. In contrast, unfunded liabilities can never be fully eliminated using the over-funding approach. ${ }^{18}$ Sensitivity analysis provided in Tables $3 \mathrm{~A}$ and 3B show that unfunded liabilities continue to be eliminated in the cases considered above under the two alternative sets of assumptions but at a cost of higher tax rates.

\section{Taxing Returns in Good States to Pay For Subsidizing Returns in Bad States}

The government could also shift some of the asset returns in the good states of the world to the bad states using explicit state-contingent taxation. For comparability, this section considers the extreme case in which the government uses a confiscatory tax to take away all assets in excess of the guaranteed benefit level. The government still guarantees a minimum benefit equal to $\chi$ times the current Social Security benefit level. Hence, the combination of the minimum benefit guarantee, along with the confiscatory tax on all returns above that same benefit level, implies that the government is promising a fixed benefit equal to $\chi$ times the current Social Security benefit. So, for example, the case $\chi=1$ corresponds to pre-funding the current Social Security system. Hence, the analysis incorporates pre-funding the current defined-benefit system - i.e., without conversion to private accounts - as a special case. ${ }^{19}$

The conversion from pay-as-you-go financing to more funding is the same as before. In particular, the mandatory contribution rate is given by equation (7') and $\beta$ fraction of these contributions are deposited in bonds and the other $(1-\beta)$ fraction goes into equities. Only a tax on

\footnotetext{
${ }^{18}$ The standardized portfolio approach also rules out the limiting absorbing state; the over-saving approach does.

${ }^{19}$ Equivalently, assets could be held by the government in a trust fund so that the government can strip off any excess returns, and subsidized low returns, in order to produce a fixed benefit. Indeed, with a confiscatory tax, investors realize that their portfolio decisions are irrelevant. So the government could save on transaction costs by keeping all the money held in a central fund. But, of course, there are several political-economy risks associated with holding assets in a central trust fund within a cash-flow budgetary framework. These include using the assets for other purposes.
} 
returns in the good states is new.

A confiscatory tax on benefits above the guaranteed level can be absorbed into the statecontingent tax shown in equation (6). Recall, that the tax shown in equation (6) was previously used to subsidize shortfalls in retirement assets. Since, in the current section, the government now collects revenue from taxes on benefits in the good states of the world, the new state-contingent tax is similar to equation (6) except without the max operator that was previously used to separate high and low returns:

$$
\tau_{t+1}^{c}=\frac{\chi \cdot \tau_{t}^{S S} w_{t} \cdot\left(1+g_{t+1}\right)-\tau^{M} w_{t} \cdot\left[\left(1+r_{t+1}\right) \cdot \beta_{t}+\left(1+e_{t+1}\right) \cdot\left(1-\beta_{t}\right)\right]}{w_{t+1}}
$$

The change in unfunded liabilities from greater funding of the fixed benefit, therefore, equals

$$
\begin{aligned}
\% \Delta_{F} & =\left\{1-\frac{E_{t}\left(M_{t} \cdot \tau_{t+1}^{c} w_{t+1}\right)}{E_{t}\left(M_{t} \cdot \tau_{t}^{s} w_{t+1}\right)}\right\} \cdot 100 \% \\
& =\left\{1-\frac{(1+r) \cdot \psi \cdot(1-\beta)}{[(1+r) \cdot \beta+(1+\bar{e}) \cdot(1-\beta)]} \cdot E_{t}\left(M_{t} \cdot\left[\frac{\chi[(1+r) \cdot \beta+(1+\bar{e}) \cdot(1-\beta)]-\psi(1+r) \beta}{\psi(1-\beta)}-\left(1+e_{t+1}\right)\right]\right) \cdot 100 \%\right. \\
& =\left(1+\frac{(1+r) \cdot \psi}{[(1+r) \cdot \beta+(1+\bar{e}) \cdot(1-\beta)]}-\chi\right) \cdot 100 \%
\end{aligned}
$$

Proposition 2. $\% \Delta_{F} \geq \% \Delta_{M}$, holding with equality $\Leftrightarrow \beta=1$ and $\psi<\chi$. I.e., for identical parameters, prefunding a fixed benefit weakly reduces ex-ante liabilities more than privatization, with equal reduction if and only if the final retirement benefit is less than guaranteed benefit level with measure one.

Proof. For any $x, x=\max [0, x]+\min [0, x] \Rightarrow \max [0, x] \geq x \Rightarrow E_{t}\left(M_{t} \cdot \max [0, x]\right)$ $\geq E_{t}\left(M_{t} \cdot x\right)$, holding with equality only if $\operatorname{Pr}(x>0)=0$. Now compare the second lines in equations (8') and (9) and substitute the expression in the max operator in (8') for $x$. Q.E.D. 
The state-contingent tax approach, equation (6"'), like the earlier standardization approach, shifts returns from the good states of the world to the bad states. Proposition 2 says that when used with or without the standardization approach, the state-contingent tax (6"') reduces unfunded liabilities even more. The reason is that, in any state where the retirement benefit exceeds the minimum, the difference is taxed away, reducing the ex-ante cost of the entire guarantee. The statecontingent tax (6"') fails to reduce ex-ante liabilities if and only if the retirement benefit does not exceed the guaranteed benefit level in every possible state of the world. That last outcome, in turn, requires that all investments are made in bonds $(\beta=1)$ and that the contribution rate is low enough to produce a small enough benefit $(\psi<\chi)$.

The intuition for Proposition 2 can also be expressed in the language of financial engineering. The fixed benefit guarantee can be decomposed into a long position in a put stock option (the max operator in the above proof) and a short position in a call option (the min operator in the proof) with the same strike price, shown in equation (9). The confiscatory tax on large returns gives the government a call option, which partially compensates it for the put option that it gives pensioners in the form of a minimum benefit guarantee. That call option is valuable, unless there is no chance for it to be "in the money," which occurs if and only if the retirement benefit is less than the guaranteed benefit level with certainty (requiring only bond investments and a low contribution rate).

It is easy to see from equation (10) that there are parameter combinations such than unfunded liabilities are reduced by more than 100 percent in the fixed benefit case (e.g., $\beta=1$ and $\psi>\chi$ ). A reduction this large might be desirable on a purely normative basis if future generations face other large liabilities stemming from other government programs (e.g., Medicare).

A reduction this large is not possible with standardization alone. The best that standardization can do is to reduce liabilities by 100 percent by guaranteeing a portfolio with enough bonds. But with an additional tax on returns in good states, as now considered, the government 
would actually collect revenue in good states. Liabilities can be reduced by more than 100 percent. Even if $\beta<1$, liabilities are reduced by more than 100 percent if the ex-ante value of the tax revenue collected in the good states exceeds the value of subsidies owed in the bad states.

These results can again be interpreted using the language of financial engineering. The firstorder conditions (5) and (6) can be combined to generate the classic put-call parity relationship. If the strike (9) equals $\$ 1(1+r)$ then the put and call options have equal worth by put-call parity. So unfunded liabilities are reduced by exactly 100 percent, i.e., the call option exactly pays for the put option. If, however, equation (9) is less than $\$ 1(1+r)$, then the call option becomes more valuable than the put option, and so unfunded liabilities are reduced by more than 100 percent. We can now turn to the calculations.

\section{$\underline{\text { Calculations }}$}

Table 2 presents calculations of the reduction in unfunded liabilities, $\% \Delta_{F}$, with a tax on benefits in the good states. First, consider cases in which the expected benefit level is set equal to the guaranteed benefit level $(\psi=\chi)$. Notice that, in this case, the reduction in unfunded liabilities is well below 100 percent, unless the bond share of assets equals one $(\beta=1)$.

For example, in the case $\{\psi=1, \chi=1, \beta=0\}$, where all investments are in equities, liabilities are reduced by only 18.3 percent. Notice that this reduction is only slightly larger than the 17.9 percent reduction stated earlier where the government guaranteed a minimum benefit but did not tax the upside. The reason that the reduction is not much larger when the government actually does tax the upside is that the strike price (9) equals $\$ 1(1+\bar{e})$ at these parameters. So equities must perform at least as expected in order to satisfy the minimum benefit level. The ex-ante cost of guaranteeing that equities will perform as expected (including the equity premium) is quite large in the presence of risk aversion, relative to the ex-ante value of the tax revenue collected in the good states. In the language of financial engineering, $\$ 1(1+\bar{e})$ is much larger than $\$ 1(1+r)$ and so the put option is 
much more valuable than the call option.

This result should give policymakers - and budget authorities - some pause. Traditional budgetary cost rules used by the US Congressional Budget Office (CBO) and the US Office of Management and Budget (OMB) focus only on expected returns. ${ }^{20}$ Under those rules, it would appear that all of Social Security's unfunded liabilities could eventually be eliminated with a twopercent contribution invested in equities. But the actual risk-adjusted reduction in liabilities would be much smaller, less than one-fifth.

Now consider the effect of over-funding the retirement benefit, by setting the contribution rate high enough to produce an expected benefit much larger than the minimum benefit. Recall that, without a tax on returns in good states, over-funding was not very effective at reducing the value of unfunded liabilities. However, with a benefit's tax in good states, over-funding becomes much more effective because the ex-ante value of tax receipts collected in good states grows in proportion to the contribution rate. For example, in the case $\{\psi=5.0, \chi=1.0, \beta=0.0\}$, unfunded liabilities are reduced by $91 \frac{1}{2}$ percent with a benefit's tax in good states, but by only 63 percent without that tax, as considered earlier. As shown analytically above, the ex-ante value of that state-contingent tax revenue can even be larger than the ex-ante value of the subsidy paid in the bad states. In this case, unfunded liabilities are reduced by more than 100 percent, as shown in several cases in Table 2 . $\mathrm{H}$ Sensitivity analysis shown in Tables $3 \mathrm{~A}$ and $3 \mathrm{~B}$ continues to confirm the ability of a statecontingent tax to reduce unfunded liabilities. But notice that the change in unfunded liabilities for the fixed benefit is the same in Tables $3 \mathrm{~A}$ and $3 \mathrm{~B}$. The reason is that the standard deviation of stock returns does not directly impact the reduction in unfunded liabilities, as shown in equation (10). Intuitively, the government now participates in the upside potential of stock returns while continuing to insure the downside. Hence, the importance of the standard deviation term itself washes out; all

\footnotetext{
${ }^{20}$ See, for example, the CBO (1999) and OMB (1999).
} 
risk is captured directly by the equity premium itself.

\section{Conclusion}

Many countries have converted their unfunded defined-benefit (DB) public pension plans to funded defined-contribution(DC) plans. Most public DC plans contain minimum benefit guarantees (DC-MB) but assets are not set aside as a reserve; the guarantees are pay-as-you-go, or unfunded. Risk management techniques must be used to contain the cost of these guarantees, especially since the guarantee itself encourages people to invest their DC-MB accounts in risky assets (Proposition 1) in order to maximize the value of the guarantee.

This paper shows that the conventional method of controlling guarantee costs in DC-MB plans - over-funding - is not terribly effective. Over-funding involves setting the contribution rate high enough so that the expected retirement benefit is much larger than the minimum benefit. This paper shows that even a very large contribution rate barely changes the value of unfunded liabilities, because it simply increases retirement benefits proportionally in all non-absorbing states of the world (with no change in absorbing states). A new risk management strategy, therefore, is needed in the new era of DC-MB plans.

This paper considers two new approaches to controlling guarantee costs. The first approach borrows an idea from the recent catastrophic insurance literature. The guarantee is placed over a "standardized" portfolio, requiring agents to accept any "basis risk" if they chose a non-standard portfolio. This approach is especially useful for smaller conversions in which at least of modest DB benefit remains. However, for large conversions from DB to DC-MB plans, in which there is little or no DB benefit remaining, the government must still worry about any "implicit guarantee" that might extend beyond the standardized portfolio (the so-called "Samaritan's Dilemma") which might entice agents to accept a lot of basis risk. The second method, therefore, uses a more brute-force approach involving state-contingent taxes: positive taxes are levied on excessive returns in the good 
states of the world and negative taxes (subsidies) are levied on returns in the bad states. Both options are very effective at controlling guarantee costs, and they can be used separately or together. Calculations demonstrate that all of the unfunded liabilities associated with modern pay-as-you-go public pension programs can be eliminated under both approaches, even at a modest contribution rate. The state-contingent tax policy can, in addition, even reduce unfunded liabilities by more than 100 percent. Reducing Social Security's liabilities by more than 100 percent might be desirable to the extent that future generations face other large liabilities (e.g., Medicare).

These two alternative methods are effective in reducing unfunded liabilities because they shift resources from the good states of the world to the bad states (and, in the process, also eliminate absorbing states). In effect, the payoff in each bad state is partly financed by reducing the payoffs in the good states. As a result, for the same contribution rate, unfunded liabilities are lower under these two remedies relative to the traditional over-funding approach which does not perform this shift. Equivalently, state-contingent taxation and standardization can achieve the same reduction in unfunded liabilities as the over-funding approach, but at a smaller payroll contribution rate. 


\section{References}

Bodie, Zvi. "Financial Engineering and Social Security Reform." In Risk Aspects of InvestmentBased Social Security Reform, John Y. Campbell and Martin Feldstein, editors, The University of Chicago Press, 2001:

Bodie, Zvi. “On the Risk of Stocks in the Long Run.” Financial Analysts Journal, May/June 1995.

Bodie, Zvi and Robert Merton. "Pension Benefit Guarantees in the United States: A Functional Analysis." Chapter 5 in R. Schmitt, ed., The Future of Pensions in the United States, University of Pennsylvania Press, 1993.

Black, F. and M.J. Scholes. "The Pricing of Options and Corporate Liabilities." Journal of Political Economy, 1973, 81(3): 637-54.

Congressional Budget Office, Social Security Privatization: Experiences Abroad, CBO Paper, Washington, DC, 1998.

Congressional Budget Office. An Analysis of the President's Budgetary Proposals for Fiscal Year 2000, April, 1999.

Doherty, Neil and Kent Smetters, "Moral Hazard and Reinsurance." Mimeo, The Wharton School, 2000 .

Feldstein, Martin and Andrew Samwick. "The Economics of Prefunding Social Security and Medicare Benefits." in B. Bernanke and J. Rotemberg (eds.) NBER Macroeconomics Annual 1997. Cambridge: MIT Press, 115-148, 1997.

Feldstein, Martin and Andrew Samwick. "Allocating Payroll Tax Revenue to Personal Retirement Accounts to Maintain Social Security Benefits and the Payroll Tax Rate." NBER Working \#7767, 2000 .

Feldstein, Martin, E. Ranguelova and Andrew Samwick. "The Transition to Investment-Based Social Security When Portfolio Returns and Capital Profitability are Uncertain." John Campbell and Martin Feldstein, Editors, Risk Aspects of Investment-Based Social Security Reform, NBER, University of Chicago Press, 2001.

Gramm, Senator. "Investment-Based Social Security." Circulated mimeo, U.S. States Senate, Washington, D.C.

Hieger, Melissa and William Shipman. "Common Objections to a Market-Based Social Security: A Response.” The Cato Project on Social Security Privatization, July 22, 1997 SSP No. 10.

Marcus, Alan J. "Corporate Pension Policy and the Value of PBGC Insurance." in Issues in Pension Economics. Bodie, Zvi, ed. Shoven, John B., ed. Wise, David A., ed., National Bureau of Economic Research Project Report series Chicago and London: University of Chicago Press. 1987, 49-76.

Marcus, Alan J. "Spinoff-Terminations and the Value of Pension Insurance." Journal of Finance, 
40, 3, 911-24, 1985.

Office and Management of Budget. The Fiscal Year 2000 Budget, Transmitted to Congress on February 1, 1999.

Pesando, James. "Investment Risk, Bankruptcy Risk, and Pension Reform in Canada." Journal of Finance, 1982, 37, 3, 741 - 49.

Smetters, Kent. "Privatizing Versus Prefunding Social Security." Mimeo, University of Pennsylvania, 1998, unpublished.

— "The Effect of Pay-When-Needed Benefit Guarantees on the Impact of Social Security Privatization." John Campbell and Martin Feldstein, Editors, Risk Aspects of Investment-Based Social Security Reform, NBER, University of Chicago Press, 2001.

Social Security Advisory Board. "Estimating the Real Rate of Return on Stocks over the Long Term.” August, 2001: Washington, DC.

Social Security Trustees, The 2000 OASDI Trustees Report, Social Security Administration, Washington, DC, 2000.

Stanton, Richard. "The Valuation of Option Features in Retirement Benefits." Journal of Financial Economics, 2000, 56: 485 - 516. 
Table 1

Variable Definitions

\begin{tabular}{|c|l|}
\hline Variable & \multicolumn{1}{|c|}{ Definition } \\
\hline$\Psi$ & Expected retirement benefit in private account $=\Psi \times$ Social Security benefit \\
$\beta$ & Guaranteed benefit in private account $=\chi \times$ Social Security benefit \\
$\exp$ & $=\beta r+(1-\beta) \bar{e}$, i.e., the expected net annual real return to private account \\
$\tau^{M}$ & Mandatory contribution (tax) rate for the new private account \\
$\% \Delta_{M}$ & Percent change in unfunded liabilities with the minimum benefit guarantee \\
$\% \Delta_{F}$ & Percent change in unfunded liabilities with the fixed benefit guarantee \\
$\hat{\Omega}$ & Value of implicit put option for the minimum benefit guarantee \\
$\bar{e}$ & Expected annual real rate of return to equities \\
$r$ & Real annual risk-free return \\
$\bar{g}$ & Average annual real rate of wage growth \\
$\sigma$ & Standard deviation of the first differences of logged real returns on the S\&P500 \\
\hline
\end{tabular}


Table 1 (Cont.)

Benchmark Parameter Assumptions

\begin{tabular}{|c|c|}
\hline Parameter & Value \\
\hline $\bar{e}$ & 0.09 \\
$r$ & 0.03 \\
$g$ & 0.01 \\
$\sigma$ & 0.16 \\
$\psi$ & (varies) \\
$\chi$ & (varies) \\
$\beta$ & (varies) \\
$\exp$ & (varies) \\
\hline
\end{tabular}


Table 2

Change in Unfunded Liabilities -

Benchmark Parameters

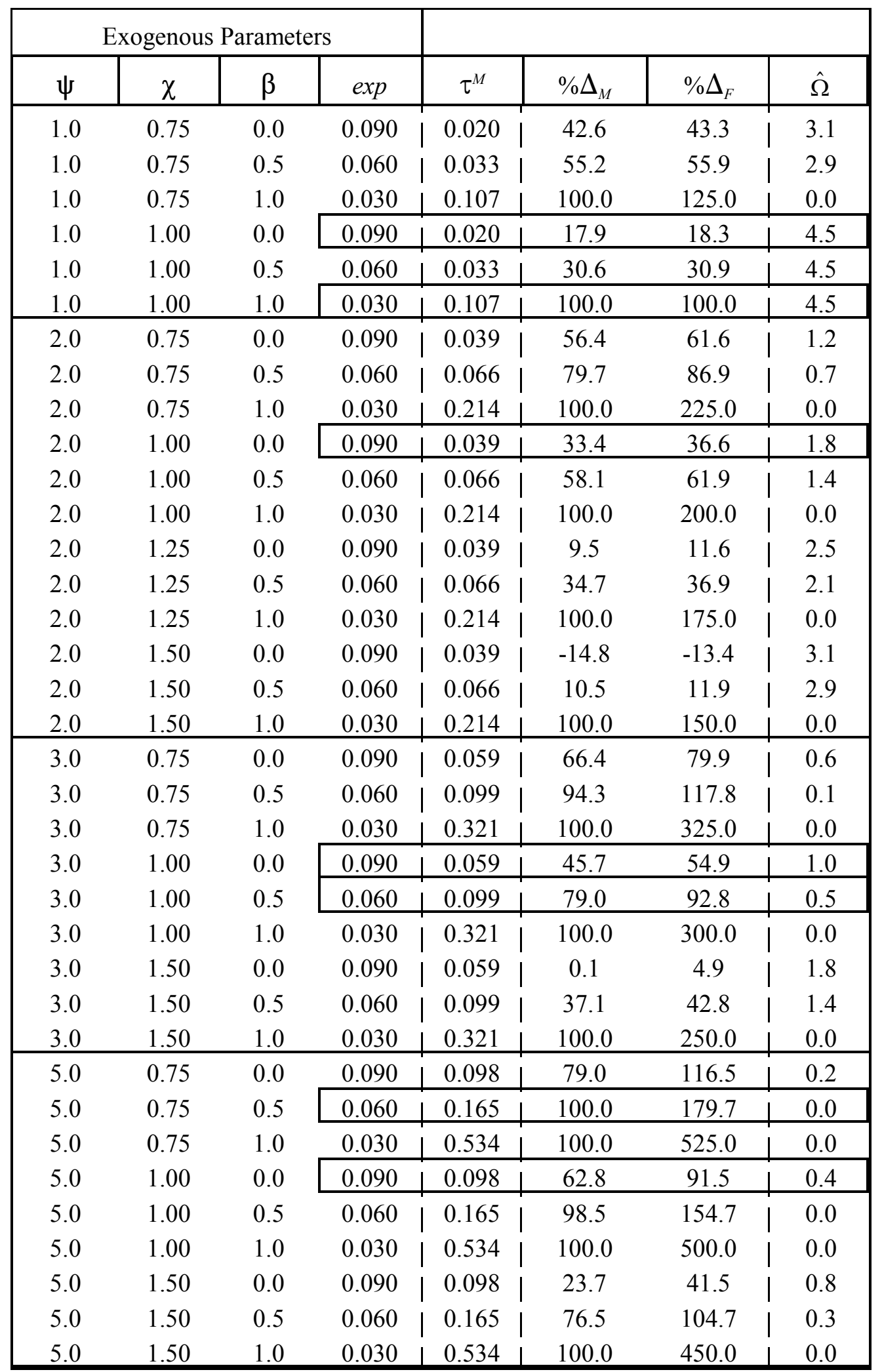


Table 3A

Change in Unfunded Liabilities -

Sensitivity Analysis ( $\bar{e}=\mathbf{0 . 0 6}$ )

\begin{tabular}{|c|c|c|c|c|c|c|c|c|}
\hline \multicolumn{4}{|c|}{ Exogenous Parameters } & \multirow[b]{2}{*}{$\tau^{M}$} & \multirow[b]{2}{*}{$\% \Delta_{M}$} & \multirow[b]{2}{*}{$\% \Delta_{F}$} & & \multirow[b]{2}{*}{$\hat{\Omega}$} \\
\hline$\psi$ & $\chi$ & $\beta$ & $\exp$ & & & & & \\
\hline 1.0 & 0.75 & 0.0 & 0.060 & 0.045 & 59.9 & 67.3 & & 0.9 \\
\hline 1.0 & 0.75 & 0.5 & 0.045 & 0.064 & 78.1 & 84.4 & & 0.7 \\
\hline 1.0 & 0.75 & 1.0 & 0.030 & 0.107 & 100.0 & 125.0 & & 0.0 \\
\hline 1.0 & 1.00 & 0.0 & 0.060 & 0.045 & 37.5 & 42.3 & & 1.5 \\
\hline 1.0 & 1.00 & 0.5 & 0.045 & 0.064 & 56.1 & 59.4 & $\perp$ & 1.5 \\
\hline 1.0 & 1.00 & 1.0 & 0.030 & 0.107 & 100.0 & 100.0 & & 1.5 \\
\hline 2.0 & 0.75 & 0.0 & 0.060 & 0.090 & 77.1 & 109.5 & & 0.3 \\
\hline 2.0 & 0.75 & 0.5 & 0.045 & 0.127 & 99.1 & 143.8 & & 0.0 \\
\hline 2.0 & 0.75 & 1.0 & 0.030 & 0.214 & 100.0 & 225.0 & & 0.0 \\
\hline 2.0 & 1.00 & 0.0 & 0.060 & 0.090 & 60.1 & 84.5 & 4 & 0.5 \\
\hline 2.0 & 1.00 & 0.5 & 0.045 & 0.127 & 90.8 & 118.8 & 1 & 0.2 \\
\hline 2.0 & 1.00 & 1.0 & 0.030 & 0.214 & 100.0 & 200.0 & ! & 0.0 \\
\hline 2.0 & 1.25 & 0.0 & 0.060 & 0.090 & 40.7 & 59.5 & & 0.7 \\
\hline 2.0 & 1.25 & 0.5 & 0.045 & 0.127 & 75.4 & 93.8 & & 0.4 \\
\hline 2.0 & 1.25 & 1.0 & 0.030 & 0.214 & 100.0 & 175.0 & & 0.0 \\
\hline 2.0 & 1.50 & 0.0 & 0.060 & 0.090 & 19.8 & 34.5 & 1 & 0.9 \\
\hline 2.0 & 1.50 & 0.5 & 0.045 & 0.127 & 56.1 & 68.8 & 1 & 0.7 \\
\hline 2.0 & 1.50 & 1.0 & 0.030 & 0.214 & 100.0 & 150.0 & & 0.0 \\
\hline 3.0 & 0.75 & 0.0 & 0.060 & 0.136 & 85.7 & 151.8 & & 0.1 \\
\hline 3.0 & 0.75 & 0.5 & 0.045 & 0.190 & 100.0 & 203.2 & & 0.0 \\
\hline 3.0 & 0.75 & 1.0 & 0.030 & 0.321 & 100.0 & 325.0 & & 0.0 \\
\hline 3.0 & 1.00 & 0.0 & 0.060 & 0.136 & 73.1 & 126.8 & & 0.2 \\
\hline 3.0 & 1.00 & 0.5 & 0.045 & 0.190 & 99.8 & 178.2 & & 0.0 \\
\hline 3.0 & 1.00 & 1.0 & 0.030 & 0.321 & 100.0 & 300.0 & 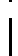 & 0.0 \\
\hline 3.0 & 1.50 & 0.0 & 0.060 & 0.136 & 40.2 & 76.8 & $\mid$ & 0.5 \\
\hline 3.0 & 1.50 & 0.5 & 0.045 & 0.190 & 86.1 & 128.2 & & 0.2 \\
\hline 3.0 & 1.50 & 1.0 & 0.030 & 0.321 & 100.0 & 250.0 & & 0.0 \\
\hline 5.0 & 0.75 & 0.0 & 0.060 & 0.226 & 93.2 & 236.3 & & 0.0 \\
\hline 5.0 & 0.75 & 0.5 & 0.045 & 0.318 & 100.0 & 322.1 & & 0.0 \\
\hline 5.0 & 0.75 & 1.0 & 0.030 & 0.534 & 100.0 & 525.0 & 1 & 0.0 \\
\hline 5.0 & 1.00 & 0.0 & 0.060 & 0.226 & 86.0 & 211.3 & 1 & 0.1 \\
\hline 5.0 & 1.00 & 0.5 & 0.045 & 0.318 & 100.0 & 297.1 & 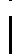 & 0.0 \\
\hline 5.0 & 1.00 & 1.0 & 0.030 & 0.534 & 100.0 & 500.0 & & 0.0 \\
\hline 5.0 & 1.50 & 0.0 & 0.060 & 0.226 & 64.2 & 161.3 & & 0.2 \\
\hline 5.0 & 1.50 & 0.5 & 0.045 & 0.318 & 100.0 & 247.1 & | & 0.0 \\
\hline 5.0 & 1.50 & 1.0 & 0.030 & 0.534 & 100.0 & 450.0 & 1 & 0.0 \\
\hline
\end{tabular}


Table 3B

Change in Unfunded Liabilities

Sensitivity Analysis ( $\bar{e}=\mathbf{0 . 0 6} ; \sigma=\mathbf{0 . 2 0}$ )

\begin{tabular}{|c|c|c|c|c|c|c|c|}
\hline \multicolumn{4}{|c|}{ Exogenous Parameters } & \multirow[b]{2}{*}{$\tau^{M}$} & \multirow[b]{2}{*}{$\% \Delta_{M}$} & \multirow[b]{2}{*}{$\% \Delta_{F}$} & \multirow[b]{2}{*}{$\hat{\Omega}$} \\
\hline$\psi$ & $\chi$ & $\beta$ & $\exp$ & & & & \\
\hline 1.0 & 0.75 & 0.0 & 0.060 & 0.045 & 56.2 & 67.3 & 1.0 \\
\hline 1.0 & 0.75 & 0.5 & 0.045 & 0.064 & 75.5 & 84.4 & 0.8 \\
\hline 1.0 & 0.75 & 1.0 & 0.030 & 0.107 & 100.0 & 125.0 & 0.0 \\
\hline 1.0 & 1.00 & 0.0 & 0.060 & 0.045 & 34.1 & 42.3 & 1.6 \\
\hline 1.0 & 1.00 & 0.5 & 0.045 & 0.064 & 53.7 & 59.4 & 1.6 \\
\hline 1.0 & 1.00 & 1.0 & 0.030 & 0.107 & 100.0 & 100.0 & 1.6 \\
\hline 2.0 & 0.75 & 0.0 & 0.060 & 0.090 & 71.1 & 109.5 & 0.3 \\
\hline 2.0 & 0.75 & 0.5 & 0.045 & 0.127 & 98.2 & 143.8 & 0.0 \\
\hline 2.0 & 0.75 & 1.0 & 0.030 & 0.214 & 100.0 & 225.0 & | 0.0 \\
\hline 2.0 & 1.00 & 0.0 & 0.060 & 0.090 & 53.1 & 84.5 & $\begin{array}{l}0.6 \\
\end{array}$ \\
\hline 2.0 & 1.00 & 0.5 & 0.045 & 0.127 & 87.3 & 118.8 & 0.2 \\
\hline 2.0 & 1.00 & 1.0 & 0.030 & 0.214 & 100.0 & 200.0 & 0.0 \\
\hline 2.0 & 1.25 & 0.0 & 0.060 & 0.090 & 33.4 & 59.5 & 0.8 \\
\hline 2.0 & 1.25 & 0.5 & 0.045 & 0.127 & 70.6 & 93.8 & 0.5 \\
\hline 2.0 & 1.25 & 1.0 & 0.030 & 0.214 & 100.0 & 175.0 & 0.0 \\
\hline 2.0 & 1.50 & 0.0 & 0.060 & 0.090 & 12.5 & 34.5 & 1.0 \\
\hline 2.0 & 1.50 & 0.5 & 0.045 & 0.127 & 51.0 & 68.8 & $\begin{array}{l}0.8 \\
\end{array}$ \\
\hline 2.0 & 1.50 & 1.0 & 0.030 & 0.214 & 100.0 & 150.0 & 0.0 \\
\hline 3.0 & 0.75 & 0.0 & 0.060 & 0.136 & 79.3 & 151.8 & 0.2 \\
\hline 3.0 & 0.75 & 0.5 & 0.045 & 0.190 & 100.0 & 203.2 & 0.0 \\
\hline 3.0 & 0.75 & 1.0 & 0.030 & 0.321 & 100.0 & 325.0 & | 0.0 \\
\hline 3.0 & 1.00 & 0.0 & 0.060 & 0.136 & 64.7 & 126.8 & $\begin{array}{l}0.3 \\
\end{array}$ \\
\hline 3.0 & 1.00 & 0.5 & 0.045 & 0.190 & 99.6 & 178.2 & 0.0 \\
\hline 3.0 & 1.00 & 1.0 & 0.030 & 0.321 & 100.0 & 300.0 & 0.0 \\
\hline 3.0 & 1.50 & 0.0 & 0.060 & 0.136 & 29.7 & 76.8 & 0.6 \\
\hline 3.0 & 1.50 & 0.5 & 0.045 & 0.190 & 80.9 & 128.2 & 0.2 \\
\hline 3.0 & 1.50 & 1.0 & 0.030 & 0.321 & 100.0 & 250.0 & $\begin{array}{r}0.0 \\
\end{array}$ \\
\hline 5.0 & 0.75 & 0.0 & 0.060 & 0.226 & 87.8 & 236.3 & $\begin{array}{l}0.1 \\
\end{array}$ \\
\hline 5.0 & 0.75 & 0.5 & 0.045 & 0.318 & 100.0 & 322.1 & $\begin{array}{l}0.0 \\
\end{array}$ \\
\hline 5.0 & 0.75 & 1.0 & 0.030 & 0.534 & 100.0 & 525.0 & $\begin{array}{l}0.0 \\
\end{array}$ \\
\hline 5.0 & 1.00 & 0.0 & 0.060 & 0.226 & 77.7 & 211.3 & $\begin{array}{l}0.1 \\
\end{array}$ \\
\hline 5.0 & 1.00 & 0.5 & 0.045 & 0.318 & 100.0 & 297.1 & 0.0 \\
\hline 5.0 & 1.00 & 1.0 & 0.030 & 0.534 & 100.0 & 500.0 & 0.0 \\
\hline 5.0 & 1.50 & 0.0 & 0.060 & 0.226 & 51.4 & 161.3 & 0.2 \\
\hline 5.0 & 1.50 & 0.5 & 0.045 & 0.318 & 100.0 & 247.1 & $\begin{array}{l}0.0 \\
\end{array}$ \\
\hline 5.0 & 1.50 & 1.0 & 0.030 & 0.534 & 100.0 & 450.0 & 0.0 \\
\hline
\end{tabular}

